\title{
Re-Deskripsi Teripang Stichopus hermanii Dari Kepulauan Karimunjawa Melalui Analisa Morfologi, Anatomi Dan Spikula (Ossicles)
}

\author{
Retno Hartati*, Widianingsih dan Umi Fatimah \\ Jurusan IImu Kelautan, Fakultas Perikanan dan Ilmu Kelautan, Universitas Diponegoro \\ JI. Prof. Soedarto, SH. Kampus UNDIP Tembalang, Semarang 50275 \\ Email : retnohartati.undip@yahoo.com
}

\begin{abstract}
Abstrak
Holothuroidea atau yang lebih dikenal dengan sebutan teripang laut atau timun laut merupakan salah satu kelas dari Echinodermata. Penampakan morfologi teripang yang hampir mirip satu dengan yang lain mengakibatkan sering terjadi kekeliruan. Penelitian ini bertujuan untuk mengkaji lebih jauh tentang identifikasi Stichopus hermanii berdasarkan morfologi, anatomi serta bentuk dan komposisi spikula yang terdapat pada teripang Stichopus hermanii. Hasil pengamatan morfologi berdasarkan bentuk, corak dan warna serta tipe spikula menunjukkan bahwa Stichopus hermanii berwarna teripang berukuran besar dengan panjang mencapai $50 \mathrm{~cm}$. Teripang ini berwarna kuning-kecoklatan dan pada papila kecil terdapat bercak keabu-abuan di seluruh permukaan tubuh dan bagian dorsal yang berbuku-buku. Bentuk dan komposisi spikula didominasi oleh bentuk roset dan meja dengan bentuk kaki empat.
\end{abstract}

Kata kunci : teripang, Stichopus hermanii, re-deskripsi, morfologi, anatomi, spikula (ossicle)

\begin{abstract}
Holothuroidea well-known as sea cucumbers is one class of Echinoderm. Morphology of sea cucumbers are almost similar to each other resulting in frequent error of identification. This study aims to re-describe of Stichopus hermanii based its on morphology, anatomy and the form and composition of the spicules. Results of morphological description based on shape, pattern and color as well as the type of spicules shows that Stichopus hermanii has yelow brownish color. The shape and composition of the spicules is dominated by a rosette shape and a table with four legs form.
\end{abstract}

Keywords : teripang, Stichopus hermanii, re-description, morphology, anatomy, spicule (ossicle)

\section{PENDAHULUAN}

Teripang merupakan salah satu komoditas perikanan yang mempunyai prospek cukup baik dan bernilai ekonomis tinggi, baik di pasaran domestik maupun internasional (Darsono, 2007). Holothuridea atau yang lebih dikenal dengan sebutan teripang atau timun laut merupakan salah satu species Echinodermata. Echinodermata memiliki lima kelas yaitu kelas Asteroide (bintang laut), kelas Ophiuroidea (bintang laut), kelas Echinoid (landak laut), kelas Crinoidea (lili laut), dan kelas Holothuridea (teripang laut) (Katili, $2011)$. Holothuridae atau teripang memiliki 3 famili yaitu famili Holothuridae ( genus Actinopyga dan Holothuria), Stichopodidae (genus Stichopus), dan Synaptidae (genus Synapta) (Hartati et al., 2011).

Teripang diklasifikasi hingga tingkat ordo berdasarkan pada jumlah dan bentuk dari tentakel yang dimilikinya. Menurut Arnold dan Birtles (1989) ordo 
Dactilokirotidia dan Molpadida memiliki bentuk tentakel digitat, ordo Aspidokirotida dan Elasipodida memiliki bentuk tentakel peltat, sedangkan ordo Apodida adalah bentuk pinat. Ordo Dactilokirotidia memiliki jumlah tentakel antara 8-30, ordo Malpadida berjumlah 15 tentakel, Ordo Apodida memiliki tentakel yang berjumlah antara $10-15$, sedangkan ordo Elasipodida tidak memiliki respiratory tree.

Identifikasi teripang hingga tingkat spesies sangat diperlukan mengingat bahwa teripang memiliki penampakan morfologi sangat mirip yang sering mengakibatkan terjadinya kekeliruan. Identifikasi teripang tidak cukup hanya dengan melihat morfologi luar teripang, namun perlu adanya analisa lebih mendalam yaitu dengan mengamati bagian anatomi dan bentuk serta komposisi spikula (ossicle). Spikula merupakan endoskeleton yang tereduksi dan tertanam dalam lapisan dermis pada dinding tubuh teripang yang berukuran mikroskopis. Spikula terbentuk dari senyawa utama kalsium karbonat yang larut dalam larutan asam. Setiap jenis teripang memiliki bentuk dan komposisi spikula yang berbeda sehingga spikula dapat dijadikan sebagai acuan pengklasifikasian teripang hingga tingkat genus dan spesies (Purwati et al., 2010). Penelitian ini bertujuan untuk melakukan re-deskripsi teripang Stichopus hermanii dari Kepulauan Karimunjawa berdasarkan morfologi, anatomi serta bentuk dan komposisi spikula (ossicle).

\section{MATERI DAN METODE}

Materi yang digunakan dalam penelitian ini adalah teripang Stichopus hermanii yang diambil dari pengepul teripang di Karimunjawa, Jepara dari hasil tangkapan nelayan di Perairan Kepulauan Karimunjawa. Metode penelitian yang digunakan yaitu metode eksplorasi dan pengambilan sampel dilakukan pada April 2015. Identifikasi dan re-deskripsi sampel dilakukan dengan tahapan antara lain : identifikasi morfologi (menganalisa panjang, berat, warna, struktur tubuh dan bentuk tubuh), identifikasi anatomi (membedah dan menganati bagian- bagian dalam tubuh dari teripang ), dan identifikasi mikroskopik dengan mengamati bentuk dan komposisi spikula (ossicle) yang diisolasi dari jaringan integumen yang dipotong sebesar 1-2 $\mathrm{cm}^{2}$ kemudian dilarutkan dengan larutan pemutih selama 10-20 menit.

Integumen yang telah dilarutkan akan menjadi endapan kemudian supernatan dibuang dan endapan spikula di bilas dengan aquades 3-5 kali. Spikula yang bersih kemudian diamati menggunakan mikroskop (Setyastuti, 2013). Hasil dari bentuk dan komposisi spikula yang ditemukan kemudian dibandingkan dengan pustaka sehingga dapat diketahui nama ilmiah dari setiap spesies teripang yang diidentifikasi ( Pawson et al, 2010).

\section{HASIL DAN PEMBAHASAN}

Di Kepulauan karimunjawa Teripang Trill juga disebut sebagai teripang (Gamet) Kasur (Hartati et al., 2013; 2015). di Berdasarkan identifikasi sampel dari Stichopus hermanii memiliki bentuk penampang tubuh secara trapesium dengan ukuran yang relatif besar. Hal ini seperti yang telah dijelaskan oleh Wirawati et al., (2007) bahwa pada umumnya famili Stichopodidae memiliki penampang tubuh berbentuk trapesium atau persegi (Gambar 1). Integumen yang tebal dan licin dengan lipatan-lipatan di bagian permukaan dorsal yang tersebar papila secara teratur pada kedua sisi dorsolateral. Bagian dorsal berwarna coklat kekuningan dengan warna papila atau tonjolan seperti kutil berwarna kehitaman.

Sedangkan bagian ventral berwarna orange dengan kaki tabung yang dominan berwarna hitam. Penampang bagian ventral terdapat garis yang memisahkan kaki tabung dari bagian tubuh kanan dan kiri teripang dengan warna orange. Bagian anterior cenderung berwarna kuning kecoklatan, dan warna tentakel berwarna kuning keputih- putihan. Namun, saat spesimen di simpan dalam alhokol warna berubah menjadi kuning dan cairan alkohol berwarna merah pekat (Hartati et al., 2009). 
Struktur tubuh bagian tubuh luar dari spesimen Stichopus hermanii pada bagian dorsal yaitu licin, tebal dan berbuku buku yang dipisahkan oleh garis amburaklar. Bagian dorsal terdapat tonjolan seperti kutil atau papila yang tersebar di seluruh bagian dorsal dari spesimen Stichopus hermanii. Bagian ventral, terdapat kaki tabung berukuran sekitar $0,5-1 \mathrm{~cm}$ tersebar diseluruh ventral spesimen.

$\begin{array}{lrr}\text { Bagian-bagian dari anatomi } & \text { and } \\ \text { Stichopus hermanii yang } & \text { lain } \\ \text { adalahtentakel, cincin kapur, polian }\end{array}$

vesicle, lambung, pohon respirasi, intestinum berwarna coklat kekuningan, dan anus. Tentakel dari teripang jenis ini berbentuk perisai (peltate) dan berwarna putih kekuningan. Tabung cuvier berwarna putih transparan dengan bentuk seperti tabung yang dapat dilihat pada (Gambar 3). Pohon respirasi yang dimiliki berwarna putih kekuningan dengan percabangan kecil, halus dan banyak sehingga terlihat mengerombol. Penampang tubuh yang memanjang dengan bentuk intestinum yang panjang berbentuk tabung dan transparan.

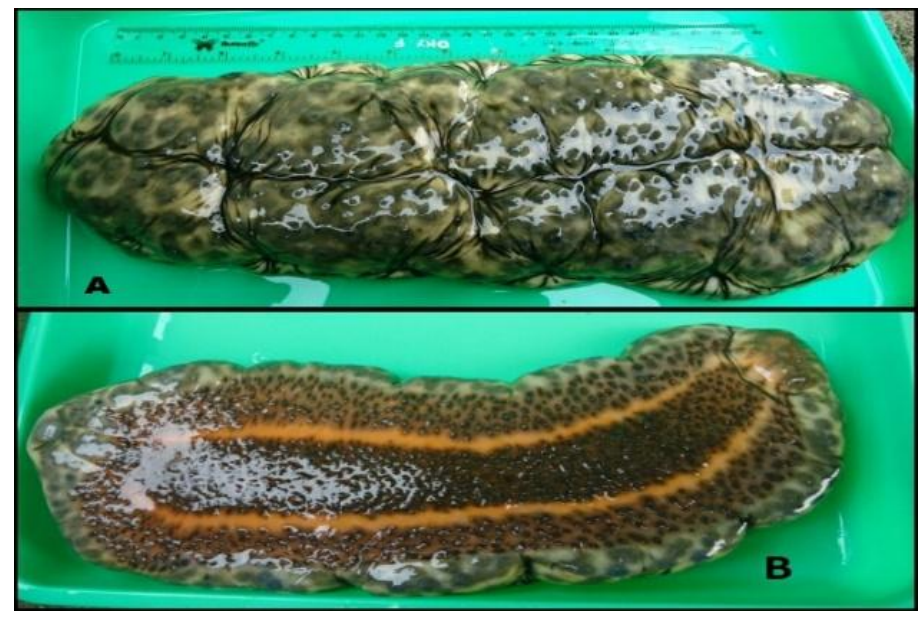

Gambar 1. Kenampakan morfologi Stichopus hermanii A : bagian dorsal, B : bagian ventral

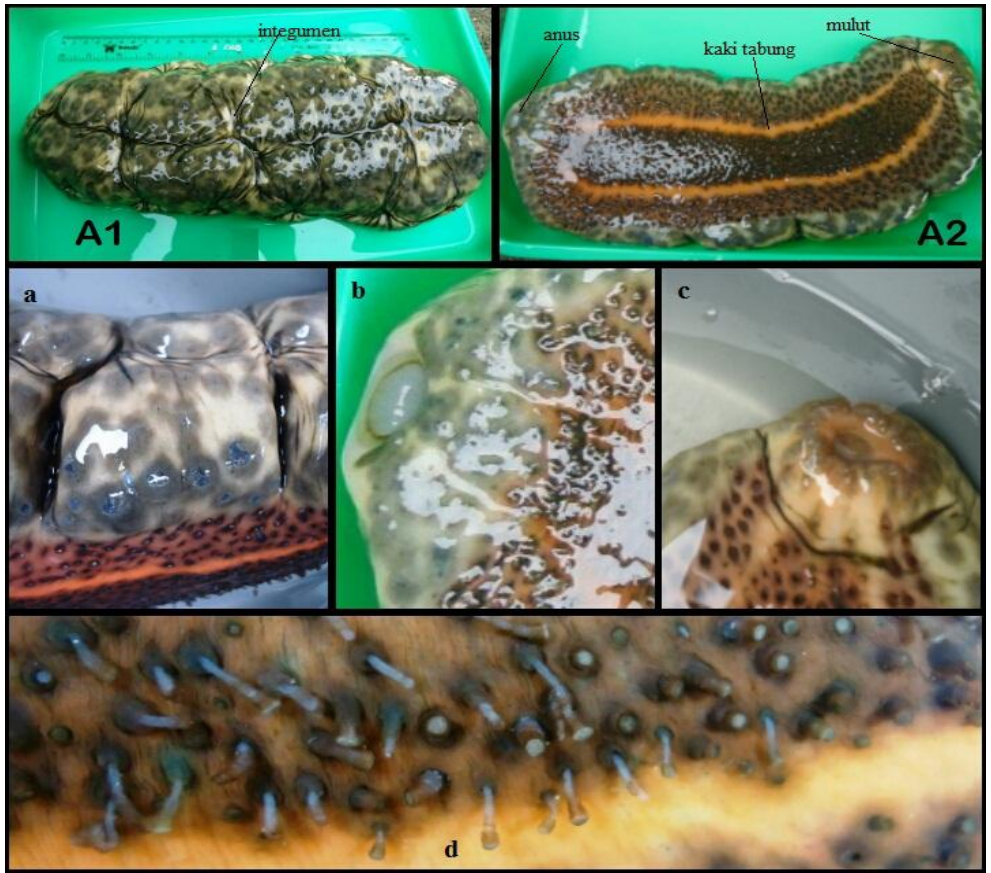

Gambar 2. Stuktur luar tubuh dari Stichopus hermanii ;

A1 : bagian dorsal, A2 : bagian ventral; a : integumen b) anus; c: mulut; $d$ : kaki tabung 


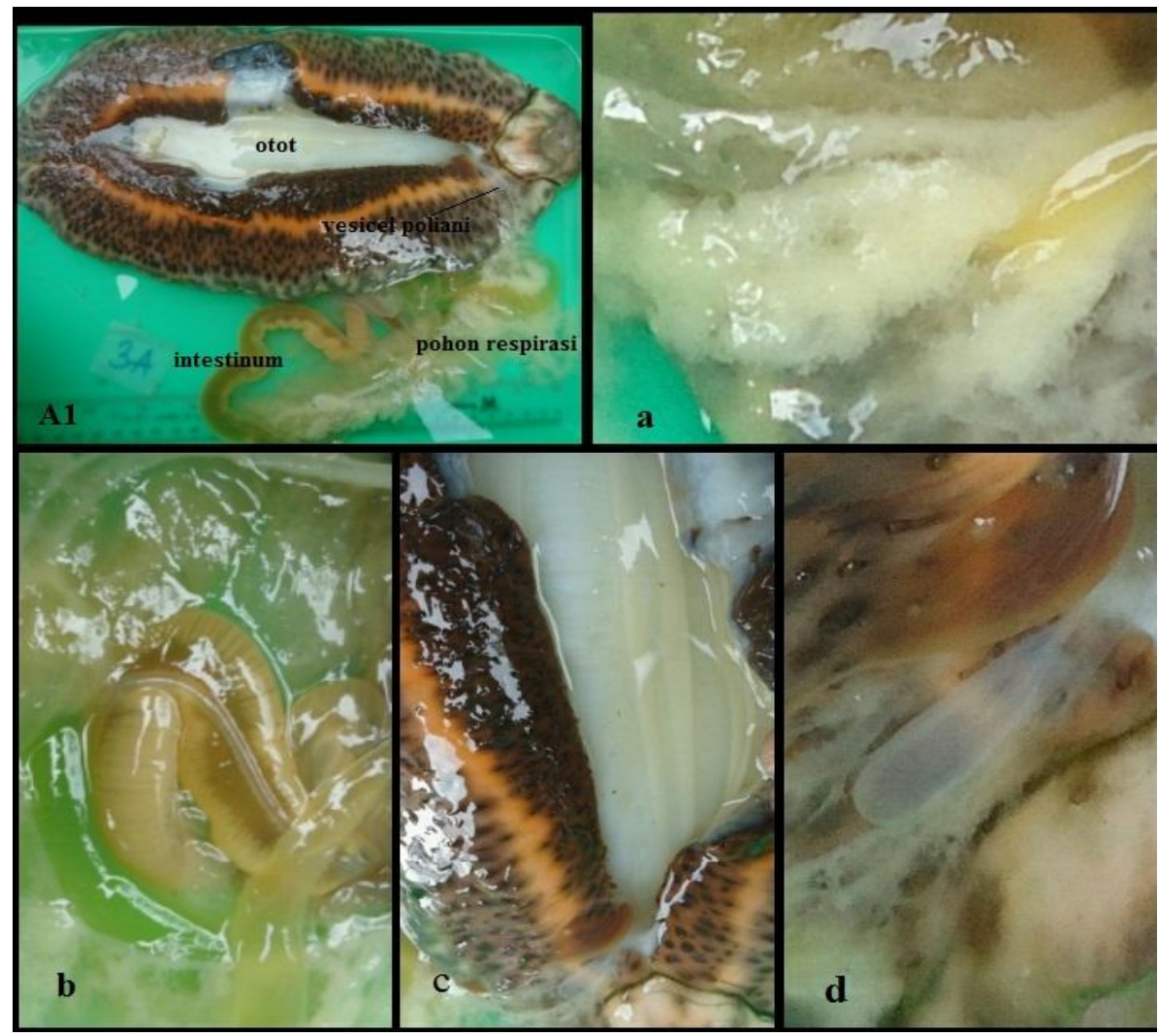

Gambar 3. Organ internal Stichopus hermanii

Al. Isi perut Stichopus hermanii; $a$ : Pohon respirasi, b : intestinum, c: otot, $d$ : polian vesicle

Massin (2002) menjelaskan bahwa papila bagian dorsal S. hermanii tersebar dengan melimpah dan kaki tabung yang tersebar diseluruh bagian ventral. Tubuh teripang memiliki posisi mulut dan tentakel yang berada di ujung anterior sedangkan di ujung satunya adalah bagian posterior yang merupakan lubang anus (Pawon ef al., 2010). Bagian mulut yang disokong dengan cincin kapur (calcareous ring) dan dilengkapi dengan tentakel yang berjumlah 20 buah dengan berbentuk perisai (peltate).Pada mulanya Stichopus hermanii merupakan Stichopus variegatus (Stichopus variegatus var. hermanii) (Samyn 2000). Rowe dan Gates (1995), Wirawati et al., 2007) menyatakan bahwa nama Stichopus variegatus tidak lagi valid. Jenis Stichopus variegatus dikelompokan dalam nama Stichopus hermanii semper, 1868. Aziz (1981), Siena, (1996), dan Saputra (2001) juga menemukan Stichopus variegatus di Kepulauan Karimunjawa.

Teripang Stichopus hermanii memiliki pohon respirasi berwarna putih kekuningan dengan cabang yang lebih halus (Gambar 3). Ruppert et al., (2004) menjelaskan bahwa pohon respirasi yang dimiliki teripang mirip dengan fungsi paru-paru pada manusia, dan pohon respirasi merupakan alat pernafasan pada teripang yang melekat pada kloaka. Spikula yang diperoleh adalah bentuk roset, tables, bentuk C, perforated dan bentuk S. Bntuk dan komposisi spikula pada Stichopus hermanii yang ditemukan didominasi oleh bentuk meja dengan kaki empat dan bentuk rosettes. Spikula tables berukuran 9$15 \mu \mathrm{m}$, rods (batang bergerigi) yang dominan ditemukan di tentakel berukuran 93- $130 \mu \mathrm{m}$ dan terminal plates (lempengan berlubang) berukuran 72- $110 \mu \mathrm{m}$.

Massin(1999) menyebutkan ukuran dari spikula Stichopus hermanii yaitu tables (meja) dengan kaki empat berdiamtere 35$65 \mu \mathrm{m}$, roset berukuran 15-55 $\mu \mathrm{m}$, rods (batang berduri dengan bagian tengah yang bercabang) berukuran 160-190 $\mu \mathrm{m}$, spikula bentuk C berukuran 95-180 $\mu \mathrm{m}$, terminal plates (lempengan berlubang ) 


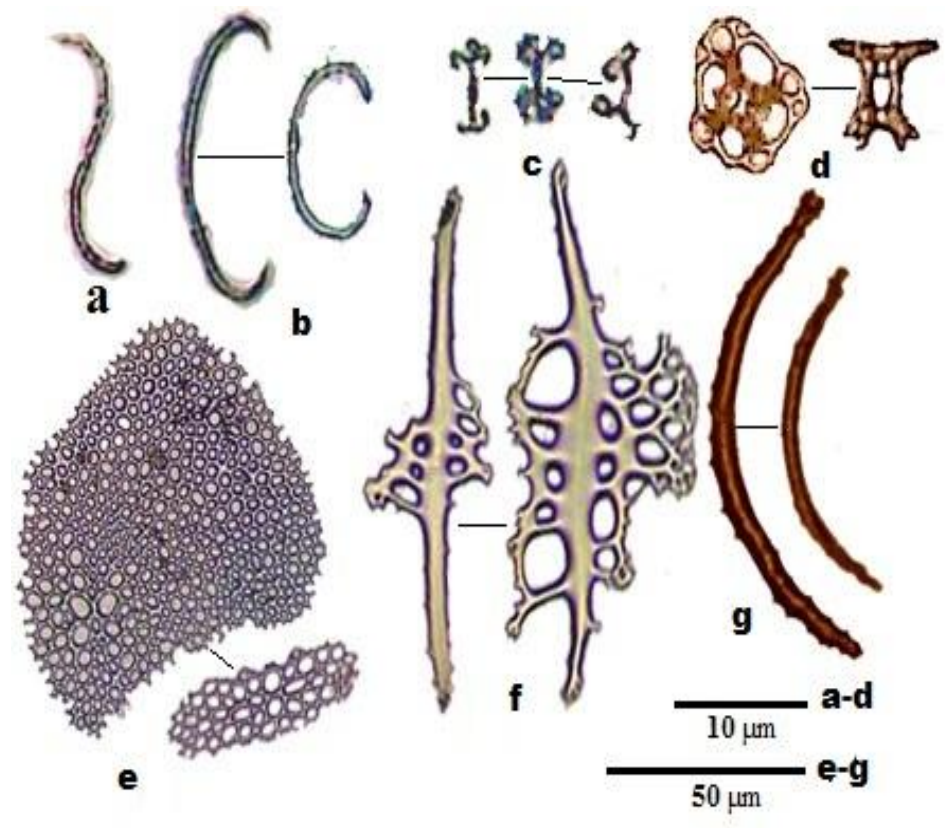

Gambar 4. Spikula Stichopus hermanii

$a$ : Bentuk S, b : Bentuk C, c : roset, d : table berkaki, e : lempengan berlubang, f: batang bercabang, $\mathrm{g}$ : batang bergerigi

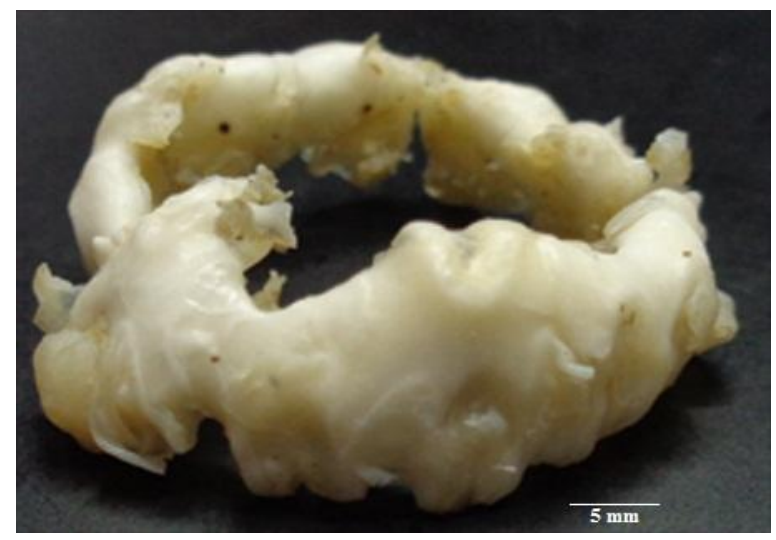

Gambar 5. Bentuk calcareous ring dari Stichopus hermanii

berukuran 50-290 $\mu \mathrm{m}$, dan rods (batang bergerigi) pada tentakel berukuran 45-600 um. Sebagian besar spikula yang ditemukan dalam identifikasi penelitian ini berada pada kisaran yang disebutkan oleh Massin (1999), meskipuan masih ada perbedaan ukuran spikula yang lebih kecil

\section{KESIMPULAN}

Berdasarkan identifikasi spikula diketahui bentuk dan komposisi yang terdapat pada Stichopus hermanii. Bentuk dan komposisi spikula yang diketahui antara lain : bentuk roset, tables, bentuk $C$, perforated dan bentuk S. Spikula bentuk meja dan roset yang mendominasi di setiap bagian dinding tubuh Stichopus hermanii. Bentuk meja yang terdapat pada Stichopus hermanii hanya bentuk meja denga kaki empat berbeda dengan bentuk meja pada Stichopus horrens yaitu bentuk meja (tables) dengan ujung yang meruncing. Berbeda dengan Stichopus hermanii, bentuk meja dengan 4 lubang denga kaki yang menyerupai kerucut. 


\section{UCAPAN TERIMAKASIH}

Penulis menyampaikan terimakasih kepada Laboratorium Biologi Laut Jurusan Ilmu Kelautan atas bantuan dan penyediaan peralatan yang dibutuhkan. Penelitian ini merupakan bagian dari penelitian skim Hibah Bersaing yang dibiayai oleh Direktur Penelitian dan pengabdian kepada Masyarakat (Ditlitabmas) Direktorat jenderal Pendidikan Tinggi (Ditjen Dikti) kementerian Pendidikan dan Kebudayaan Tahun Anggaran 2015, melalui Daftar Isian pelaksanaan Anggaran (DIPA) Direktorat Penelitian pengabdian kepada Masyarakat Nomor DIPA023.04.1.673453 /2015, tanggal 14 November 2014, DIPA Revisi 01 tanggal 03 Maret 2015

\section{DAFTAR PUSTAKA}

Darsono, P. 2007. Teripang (Holothuridea) : Kekayaan Alam dalam Keragaman Biota Laut. Oseana., 32: 1-10

Hartati, R., Widianingsih, Pradina Purwati. 2009. Teripang (Holothuroidea : Echinodermata) di Indonesia : Biologi, Budidaya dan Konservasinya. Penerbit Navila Idea. Yogyakarta. 72 hal.

Hartati, R., Widianingsih, P. Purwati. 2011. Field Guide Timun Laut di Kepulauan Karimunjawa. Jurusan IImu Kelautan, Fakultas Perikanan dan IImu kelautan, Universitas Diponegoro. 37 hal.

Hartati, R., Widianingsih, and Pradina Purwati. 2013. Fission Reproduction of Two Stichopudidae Species (Holothuria:Echinodermata). IImu Kelautan 18(2) : $112-118$.

Hartati, R., Widianingsih, dan Hadi Endrawati. 2015. Rcovery Perfomance Teripang Trill, Stichopus hermanii, (STICHOPODIDAE : HOLOTHUROIDEA : ECHINODERMATA) Setelah fission. Seminar Nasional Tahunan Ke XII Hasil Penelitian Perikanan dan Kelautan.
Universitas Gadjahmada, 8 Agustus 2015.

Massin, C. 1999. Reef-dwelling Holothuridea (Echinodermata) of the Spermonde Archipelago ( South-West Sulawesi, Indonesia). Zoologische Verhandelingen, Leiden. (329): 1 - 144.

Massin, C., Zulfigar, Y., Hwai, T.S., Boss, S.Z. 2002. The Genus Stichopus (Echinodermata: Holothuridea) from The Johore Marine Park (Malaysia) with The Description of Two New Species. Biologie 72:73-99.

Purwati, P., Retno Hartati dan Widianingsih. 2010. Eighteen Sea Cucumber Species Fished in Karimunjawa Islands, Java Sea. Mar. Res. Ind., 35(2): 10-15.

Pawson, D. L., D. J. Pawson and R. A. King. 2010. A Taxonomic Guide to The Echinodermata of The South Atlantic Bight, USA: 1. Sea Cucumbers (Echinodermata: Holothuridea). Zootaxa., 2449: 1-48

Ruppert, E.E., Fox, R.S. and Barnes, R.D. 2004. Invertebrate Zoology. Seventh Edition. Thomson, Brooks/Cole.: vii-xvii, 1-963, 11-126.

Samyn Y., D. Vandenspiegel and C., Massin. 2006. Taxonomie des Holothuries des Comores. Belgique: Abc Taxa.130pp.

Setyastuti, A. 2013. Taxonomy study on trepang collected from Karimunjawa, Situbondo,Spermonde and Ambon. Thesis. $122 \mathrm{pp}$.

Wirawati, I., A. Setyastuti \& P. Purwati. 2007. Timun Laut Anggota Famili Stichopodidae ( Aspidochirotida, Holothuroidea, Echinodermata) Koleksi Puslit Oseanologi LIPI Jakarta. Oseanologi dan Limnologi Di Indonesia.

Wulandari, N., K. Majiana dan E. Dewi. 2012. Keragaman Teripang Asal Pulau Pramuka Kepulauan Seribu Teluk Jakarta. Unnes J. Life. Sci., 1 (2): 133139. 